\title{
Relationship between ganglioside expression and anti-cancer effects of the monoclonal antibody against epithelial cell adhesion molecule in colon cancer
}

\author{
Dong Hoon Kwak', Jae-Sung Ryu' ${ }^{2}$, \\ Chang-Hyun Kim ${ }^{3}$, Kisung $\mathrm{Ko}^{2}$, \\ Jin Yeul Ma ${ }^{1}$, Kyung-A Hwang ${ }^{4}$ \\ and Young-Kug Choo ${ }^{2,5}$ \\ ${ }^{1}$ Center for Herbal Medicine Improvement Research \\ Korea Institute of Oriental Medicine \\ Daejeon 305-811, Korea \\ ${ }^{2}$ Department of Biological Science \\ College of Natural Sciences \\ Institute of Biotechnology \\ Wonkwang University \\ Iksan 570-749, Korea \\ ${ }^{3}$ Dong-guk University Research Institutes of Biotechnology \\ Medical Science Research Center \\ Goyang 410-773, Korea \\ ${ }^{4}$ Department of Agrofood Resources \\ National Academy of Agricultural Science, RDA \\ Suwon 441-853, Korea \\ ${ }^{5}$ Corresponding author: Tel, 82-63-850-6087; \\ Fax, 82-63-857-8837; E-mail, ykchoo@ wonkwang.ac.kr \\ http://dx.doi.org/10.3858/emm.2011.43.12.080
}

Accepted 28 October 2011

Available Online 28 October 2011

Abbreviations: ATCC, American type culture collection; CNS, central nerve system; CRC, colorectal carcinoma; DNR, daunorubicin; EpCAM, epithelial cell adhesion molecule; HPTLC, high-performance thin-layer chromatography; PMSF, phenylmethylsulfonyl fluoride; TUNEL, TdT-mediated duTP nick and labeling

\footnotetext{
Abstract

The human colorectal carcinoma-associated GA733 antigen epithelial cell adhesion molecule (EPCAM) was initially described as a cell surface protein selectively expressed in some myeloid cancers. Gangliosides are sialic acid-containing glycosphingolipids involved in inflammation and oncogenesis. We have demonstrated that treatment with anti-EpCAM mAb and RAW264.7 cells significant inhibited the cell growth in SW620 cancer cells, but neither anti-EpCAM mAb nor RAW264.7 cells alone induced cytotoxicity. The relationship between ganglioside expression and the anti-cancer effects of anti-EpCAM mAb and RAW264.7
}

was investigated by high-performance thin-layer chromatography. The results demonstrated that expression of GM1 and GD1a significantly increased in the ability of anti-EpCAM to inhibit cell growth in SW620 cells. Anti-EpCAM mAb treatment increased the expression of anti-apoptotic proteins such as Bcl-2, but the expression of pro-apoptotic proteins Bax, TNF- $\alpha$, caspase-3, cleaved caspase-3, and cleaved caspase-8 were unaltered. We observed that anti-EpCAM mAb significantly inhibited the growth of colon tumors, as determined by a decrease in tumor volume and weight. The expression of anti-apoptotic protein was inhibited by treatment with anti-EpCAM mAb, whereas the expression of pro-apoptotic proteins was increased. These results suggest that GD1a and GM1 were closely related to anticancer effects of anti-EpCAM $\mathrm{mAb}$. In light of these results, further clinical investigation should be conducted on anti-EPCAM mAb to determine its possible chemopreventive and/or therapeutic efficacy against human colon cancer.

Keywords: antibodies, monoclonal; apoptosis; colon neoplasms; EPCAM protein, human; gangliosides; macrophages

\section{Introduction}

The use of mAbs as adjuvant in cancer chemotherapy has drawn considerable interest because of the success of several novel agents with a broad range of targets. Although several immunological agents have been discovered, a comprehensive understanding of the mechanism of action, the optimal dose, or administration timing is absent (Dyer, 1999; Sievers et al., 2001; Dillman, 2002). Models based on tumor destruction by antigendependent cell-mediated cytotoxity or by complementdependent cytotoxicity and idiotypic networks have been developed to explain the effectiveness of mAbs. A mAb directed against epithelial cell adhesion molecule (EpCAM) is currently under development.

The human colorectal carcinoma (CRC)-associated antigen GA733, also named CO17-1A/EpCAM/ $\mathrm{KSA} / \mathrm{KS} 1-4$, is highly expressed in human CRCs and is a useful passive immunotherapy target in CRC patients (Koprowski et al., 1979; Zaloudik et 
A

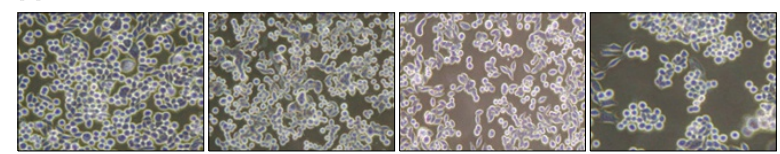

B

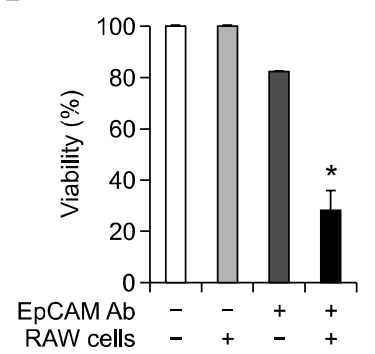

Figure 1. Morphological changes in and cell viability of SW620 human colon cancer cells treated with EpCAM mAb and RAW264.7 cells. (A) SW620 colon cancer cells morphology. (B) Viability of SW620 human colon cancer cells were treated with EpCAM mAb $(10 \mu \mathrm{M})$ and RAW 264.7 cells for $24 \mathrm{~h}$. Treatment ratio of SW620 cells and RAW264.7 cells is 1:10. Values are the mean (SD) of 3 experiments, each performed in triplicate. ${ }^{*} P<0.05$ indicates a statistically significant difference from the control.

al., 2002). The glycoprotein was originally defined by anti-GA733, anti-CO17-1A, and anti-EpCAM mAbs, which bind to different epitopes on this antigen (Herlyn et al., 1984; Ross et al., 1986). EpCAM, a putative adhesion molecule, was initially described as a cell surface protein selectively expressed by epithelial (Helyn et al., 1979; Howard et al., 1986) and some myeloid cancers (Bergsagel et al., 1992). Malignant epithelial-derived tumors significantly expressed to the EpCAM (Barzar et al., 1999). Recently, Maetzel et al. (2009) described proteolytic fragments of EpCAM that participate in nuclear signaling in tumor cells. EpCAM is also expressed by stem cells in colon cancers (Dalerba et al., 2007) and hepatocellular carcinomas (Yamashita et al., 2007).

Cell membrane constituent, such as gangliosides, modulate these complex interactions by inhibiting receptor dimerization or through other allosteric interactions. Gangliosides, which are sialic acidcontaining glycosphingolipids, are plasma membrane constituents of all vertebrate cells and are particularly abundant in the CNS (Svennerholm, 1980). In vitro, exogenously applied gangliosides are rapidly incorporated into the plasma membrane and are responsible for numerous biological effects, such as development, differentiation, and cell-cell interaction, inflammation and oncogenesis (Laine and Hakomori, 1973; Feizi, 1985; Hakomori, 1996). Subsequent studies have indicated the functional significance of tumor-associated carbohydrate antigens in cancer malignancy (Fukuda, 1996). Tumor-associated
A

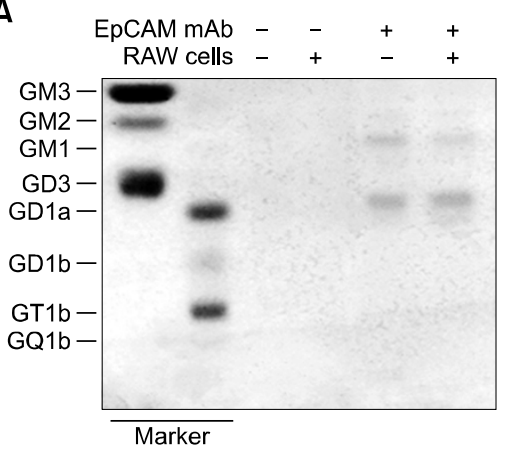

B

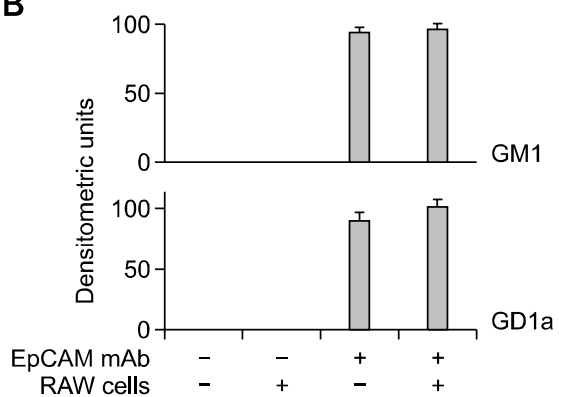

Figure 2. HPTLC profiles of Gangliosides in SW620 colon cancer cells treated with EpCAM mAb and RAW264.7 cells. (A) Qualitative analysis of gangliosides in SW620 cells, and ganglioside extracts were resolved by HPTLC. Lanes 1 and 2, ganglioside standard markers (M1 and M2); lane 3, SW620 colon cancer cells (control); lane 4, SW620 colon cancer cells treated with RAW264.7 cells; lane 5, SW620 colon cancer cells treated with EpCAM mAb; lane 6, SW620 colon cancer cells treated with EpCAM $\mathrm{mAb}$ and RAW264.7 cells. (B) Quantitative analysis of gangliosides (GM1 and GD1a) expression in SW620 colon cancer cells treated with EpCAM mAb and RAW264.7 cells. The Quantitative values from densitometry program (Beta 4.0.3 of Scion Image, Frederick, MD). Similar observations were made in 3 separate experiments.

carbohydrate determinants have been utilized as tumor markers to diagnose colon cancer (Kannagi et al., 2004). GD1a and GM1 are the 2 main gangliosides in many cell types (Kwak et al., 2011). Developmental changes in ganglioside composition of the nervous system are characterized by an increase in GM1 and GD1a during the transition from fetal to postnatal life (Svennerholm et al., 1989). Decreased GM1 reduced the natural killer activity of hepatic mononuclear cells and increased the number of hepatic metastases of colon carcinoma (Shiratori et al., 1992). Previous study has described the inhibitory effect of GM1 in animal models of colon cancer metastasis (Vogel et al., 1996). GD1a is also known to suppress the metastasis of cancer cells (Hyuga et al., 1999). In this study, we demonstrated the relationship between GM1 and GD1a expression and the anticancer effects of anti-EpCAM mAb on SW620 colorectal cancer cells and tumors. 


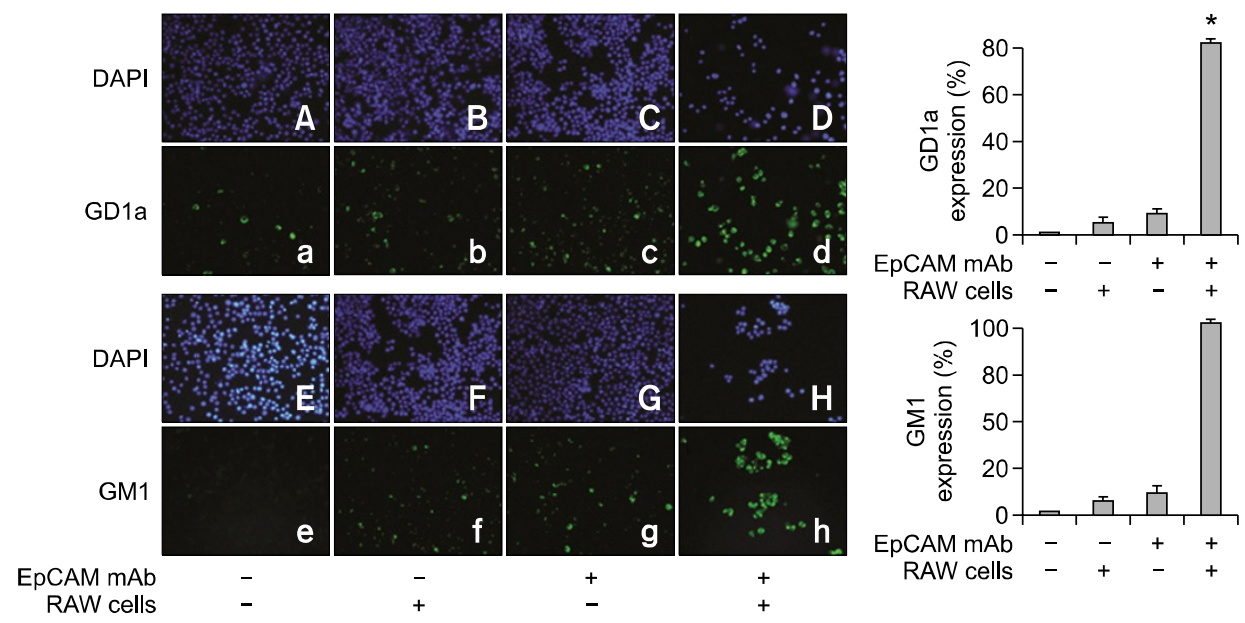

Figure 3. Effect of EpCAM mAb on the expression of gangliosides in colon cancer cells analyzed by immunofluorescence staining. Ganglioside expression in SW620 cancer cells was determined by DAPI staining and FITC (green) assay. Treatment with anti-EpCAM mAb (10 $\mu \mathrm{M})$ for $24 \mathrm{~h}$. (A) The FITC-positive (green) cells are a ganglioside GD1a expressed cells (200× magnification). (B) The FITC-positive (green) cells are a ganglioside GM1 expressed cells $\left(200 \times\right.$ magnification). The values represent mean (SD) of 3 experiments, each performed in triplicate. ${ }^{*} P<0.05$ indicates a statistically significant difference from the control group.

\section{Results}

\section{Anti-EpCAM mAb inhibited the growth of human colorectal cancer cells treated with RAW264.7 cells}

To determine whether the immunoreaction of anti-EpCAM mAb with RAW264.7 cells is inhibited to cancer cell growth, the inhibitory effect of anti-EpCAM mAb on SW620 cancer cell growth was analyzed by direct counting. Morphological observation revealed that the cells gradually reduced in size and adopted a round shape in response to anti-EpCAM mAb treatment (Figure 1A). Cell growth inhibition by immunoreaction of anti-EpCAM mAb with RAW264.7 cells was also confirmed by trypan blue dye exclusion. Moreover, treatment of SW620 cells with anti-EpCAM mAb $(10 \mu \mathrm{M})$ and RAW264.7 cells resulted in significant inhibition of cell growth (Figure 1B). However, treatment with either anti-EpCAM mAb or RAW264.7 cells alone was not cytotoxic to SW620 cancer cells.

\section{HPTLC and immunofluorescence analysis of ganglioside expression altered by treatment with anti-EpCAM mAb and RAW264.7 cells}

HPTLC analysis was performed on gangliosides extracted from 4 different treatment groups: (line 1) untreated, control SW620 colorectal cancer cells; (line 2) cells treated with anti-EpCAM mAb; (line 3) cells treated with RAW264.7 cells; and (line 4) cells treated with anti-EpCAM mAb and RAW264.7 cells. In several prestudies, gangliosides were found to play anticancer roles in cancer cells.
However, these studies could not completely exclude possible side effects induced by the chemicals used; hence, the specific roles of gangliosides in cancer cells remain unclear. Therefore, the relationship between gangliosides expression and the anticancer effects of treatment with anti-EpCAM $\mathrm{mAb}$ and RAW264.7 cells was investigated by HPTLC analysis. The results from the analysis suggest that GM1 and GD1a were closely related in anti-EpCAM mAb-mediated growth inhibition of SW620 cells (Figure 2). Figure 3 shows immunofluoresces stain result that the expression of GM1 and GD1a were significantly increased in growthinhibited SW620 cells treated with anti-EpCAM $\mathrm{mAb}$ and RAW264.7 cells.

\section{Apoptotic cell death induced by anti-EpCAM mAb and apoptotic regulatory protein expression}

To determine whether the inhibition of SW620 cell growth by anti-EpCAM mAb was due to the induction of apoptotic cell death, we evaluated the changes in apoptosis by double staining with DAPI and TUNEL; we then examined the TUNEL-labeled cells under a fluorescence microscope. The frequency of TUNEL-labeled cells and fluorescence intensity increased in treated cancer cells. Apoptotic cell numbers (DAPI-positive, TUNEL-stained cells) increased to $76(8 \%)$ in SW620 cells treated with $10 \mu \mathrm{M}$ anti-EpCAM mAb and RAW264.7 cells (Figure 4A). Further, treatment with anti-EpCAM $\mathrm{mAb}$ induced expression of apoptotic regulatory proteins. An investigation of the relationship between the induction of apoptosis and the 

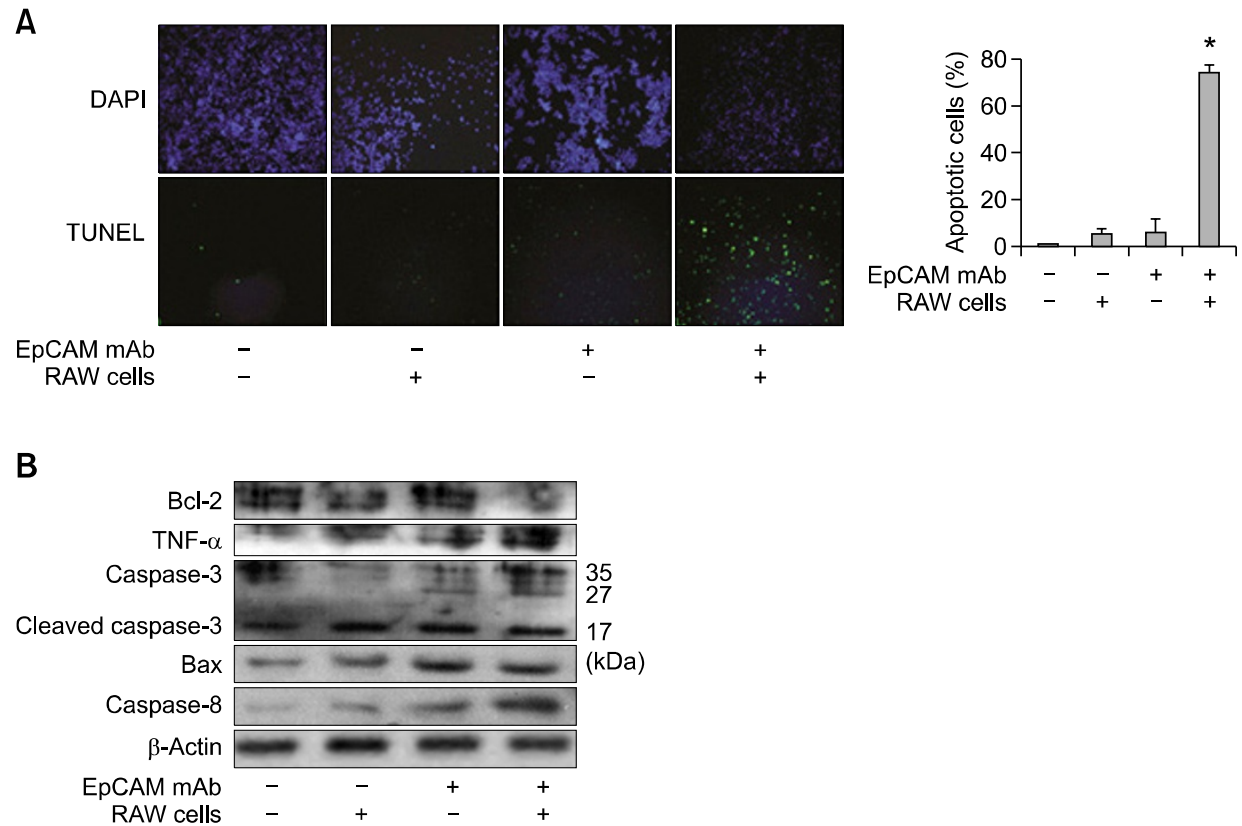

Figure 4. Effects of EpCAM mAb on the induction of apoptosis in colon cancer cells analyzed by DAPI and TUNEL staining. Apoptotic cell death was determined by DAPI staining and TUNEL assay. Treatment with anti-EpCAM mAb $(10 \mu \mathrm{M})$ and RAW 264.7 cells for $24 \mathrm{~h}$ caused apoptosis; characterized by marked chromatin condensation, small membrane-bound bodies (apoptotic bodies), cytoplasmic condensation, and cellular shrinkage. (A) The TUNEL-positive (green) cells are a apoptotic cells $(200 \times$ magnification). Apoptotic cells (DAPI-stained TUNEL-positive cells) were estimated by direct counting of fragmented nuclei after DAPI and TUNEL staining. SW620 colon cancer cells $\left(2 \times 10^{6} / \mathrm{ml}\right)$ either untreated or treated with doses of anti-EpCAM mAb $(10 \mu \mathrm{M})$ and RAW264.7 cells. An equal amount of total protein ( $40 \mu \mathrm{g} / \mathrm{lane}$ ) was subjected to $12 \%$ SDS-PAGE. (B) Expression of Bax, caspase-3, caspase-8, Bcl-2, TNF- $\alpha$, and $\beta$-actin were detected by western blotting using specific antibodies. Here, $\beta$-actin protein was used as an internal control. Each band is representative of 3 independent experiments. Values represent mean (SD) of 3 experiments, each performed in triplicate. ${ }^{*} P$

$<0.05$ indicates a statistically significant difference from the control group.

expression of apoptotic regulatory proteins by anti-EpCAM mAb showed that the expression of anti-apoptotic proteins such as Bcl-2 was decreased by treatment with anti-EpCAM mAb, whereas the expression of the pro-apoptotic proteins Bax, TNF- $\alpha$, caspase- 3 , cleaved caspase- 3 , and cleaved caspase-8 were increased by treatment with anti-EpCAM mAb (Figure 4B).

\section{Synergic effects in apoptotic cell death of SW620 cells by addition of gangliosides (GM1 and GD1a)}

To determine whether the synergic effects of gangliosides (GM1 and GD1a) co-treatment in immunoreaction of anti-EpCAM mAb with RAW264.7 cells is significantly inhibited to cancer cell growth, the inhibitory effect of anti-EpCAM mAb on SW620 cancer cell growth was analyzed by direct counting. Moreover, co-treatment of SW620 cells with anti-EpCAM mAb (10 $\mu \mathrm{M})$, RAW264.7 cells and ganliosides (GM1 and GD1a, $10 \mu \mathrm{M}$ ) resulted in significant inhibition of cell growth compared to co-treatment with anti-EpCAM mAb and RAW264.7 cells (Supplemental Data Figure S1A). However, treatment with either anti-EpCAM mAb or
RAW264.7 cells or gangliosides (GM1 and GD1a) alone was not cytotoxic to SW620 cancer cells. To determine whether the inhibition of SW620 cell growth by co-treatment of anti-EpCAM mAb, RAW264.7 cells and $10 \mu \mathrm{M}$ gangliosides (GM1 and GD1a) was due to the induction of apoptotic cell death, we evaluated the changes in apoptosis by TUNEL kit. Apoptotic cell numbers (TUNEL-stained cells) increased to $80 \%$ in SW620 cells co-treated with $10 \mu \mathrm{M}$ anti-EpCAM mAb, RAW264.7 cells and $10 \mu \mathrm{M}$ gangliosides (GM1 and GD1a) (Supplemental Data Figure S1B).

\section{Anti-EpCAM mAb inhibited the growth of colon cancer cells in an in vivo xenograft model}

Changes in body weight between the control and anti-EpCAM mAb-treated mice $(n=10)$ were not significantly different. Figure 5 shows the relative delay in tumor growth in the anti-EpCAM mAb-treated and control groups. On day 28, the final tumor volume (size) and weight were recorded. Tumor volume (size) in mice treated with anti-EpCAM mAb (100 $\mu \mathrm{g} / \mathrm{mouse})$ and daunorubicin (100 $\mu \mathrm{g} / \mathrm{mouse})$ was decreased $40 \%$ and $30 \%$ compared with the 
A

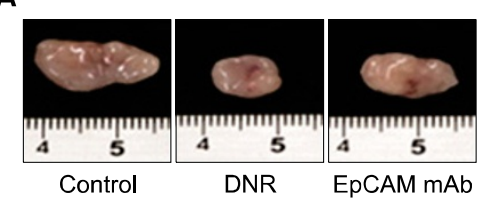

B

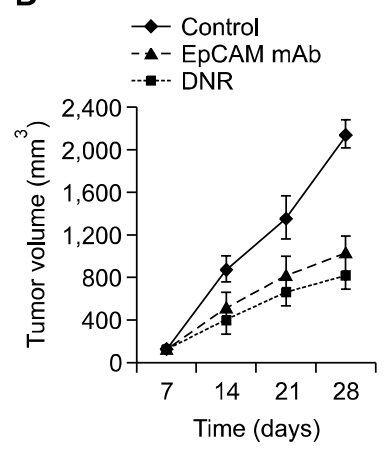

C

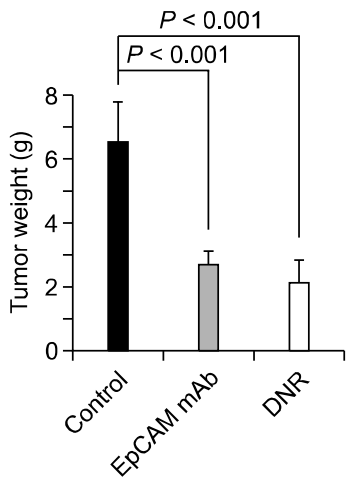

Figure 5. In vivo efficacy of anti-EpCAM mAb for inhibition of tumor growth in nude mice. (A) Differential volume (size) and morphology of inhibited tumor. (B) Tumor volumes (size) were recorded at 7, 14, 21, and 28 days after injection. (C) Tumor weight was recorded after excision. SW620 human colon cancer cells $\left(2 \times 10^{6}\right)$ were injected subcutaneously (s.c.) into each mouse (thymus-deficient BALB/c nu/nu mice). After tumor cell inoculation, each experimental group of 10 mice received i.p. injections of anti-EpCAM mAb, and DNR as a positive control, respectively ( $100 \mu \mathrm{g}$ of the mAb every 2 days).

control group, respectively (Figures $5 \mathrm{~A}$ and $5 \mathrm{~B}$ ). Tumor weight in mice treated with anti-EpCAM (100 $\mu \mathrm{g} /$ mouse) was decreased $35 \%$ compared with the control group (Figure 5C). The florescence intensity and number of TUNEL-labeled cells increased in tumors treated with anti-EpCAM mAb (Figure 6A). The immunohistochemical analysis of tumor sections by $H \& E$ and by proliferation antigens against GD1a and GM1 revealed that anti-EpCAM $\mathrm{mAb}$ at doses of $100 \mu \mathrm{g} /$ mouse inhibited tumor cell growth (Figure 6B). These results suggested that anti-EpCAM mAb suppressed colon cancer cell growth in vivo. To determine whether the inhibition of SW620 tumor growth by anti-EpCAM mAb resulted from the induction of apoptotic cell death, we evaluated the changes in apoptotic cell death by using DAPI and TUNEL double staining. Anti-EpCAM mAb treatment in SW620 tumors inhibited the expression of anti-apoptotic proteins such as $\mathrm{Bcl}-2$, but the expression of pro-apoptotic proteins, including Bax, caspase-3, cleaved caspase-3, and caspase-8, increased (Figure 6C).

\section{Discussion}

Our findings showed that the anti-EpCAM mAbmediated suppression of colon cancer cell growth in vitro is associated with the induction of apoptotic cell death. We also found that the anti-EpCAM mAb-mediated induction of GM1 and GD1 overexpression in vitro is associated with the inhibition of cancer cell growth. In vivo xenograft studies showed that anti-EpCAM mAb treatment resulted in reduced tumor weight and volume accompanied by apoptotic cell death and increased expression of pro-apoptotic cell death proteins.

EpCAM is an oncofetal tumor antigen that is abundantly expressed in CRCs and can induce natural antitumor immunity. EpCAM expression levels correlate with the proliferative activity of intestinal cells and inversely correlate with their differentiation (Wenqi et al., 2009). EpCAM has been an excellent source of anticancer vaccines because of its immunogenicity in humans (Staib et al., 2001). Anti-EpCAM mAb $(10 \mu \mathrm{M})$ inhibited the growth of colon cancer cells treated with RAW264.7 cells. This result suggests that anti-EpCAM mAb inhibits colorectal cancer cell growth by immunobinding with RAW264.7 cells.

Many anti-apoptosis genes (e.g., $\mathrm{Bcl}-\mathrm{XL}, \mathrm{Bcl}-2$ ), the TNF receptor-associated proteins 1 and 2 , and pro-apoptosis genes (e.g., caspase- 3 and -9 and Bax) are regulated in a variety of solid colon tumor cells (Schoemaker et al., 2002; Coffey et al., 2002). The Bax gene product dimerizes with Bcl-2 and prevents it from blocking apoptosis (Zha et al., 1996). The Bax protein controls cell death by activating caspase- 8 and -3 (Seol et al., 2001). We showed that anti-EpCAM mAb significantly and effectively induced apoptotic cell death in colon cancer cells. The activation of caspase- 3 and -8 was more significantly increased in SW620 colorectal cancer cells treated with anti-EpCAM mAb and RAW264.7 cells. These results suggest that in SW620 cells the anticancer effects of anti-EpCAM $\mathrm{mAb}$ may be related to apoptotic cell death. We also observed that the expression of GM1 and GD1a was significantly increased in apoptotic SW620 cells. Previous studies have reported that gangliosides have bioactive effects in immunoreactions and tumor progression (Shah et al., 1996) and that GD1a regulates metastasis of cancer cells (Hyuga et al., 1997). Our results suggest that induced the overexpression of GM1 and GD1a by anti-EpCAM mAb was closely related to increase of apoptotic cell death in SW620 colon cancer cells (Supplemental Data Figure S1).

Anti-EpCAM mAb significantly inhibited the growth of colon tumors as determined by a decrease 
$\mathbf{A}$

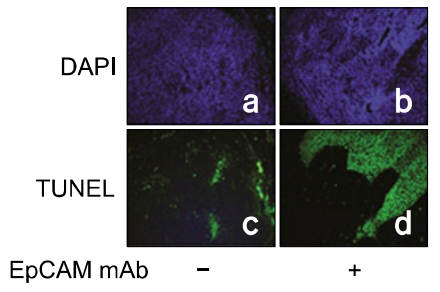

B
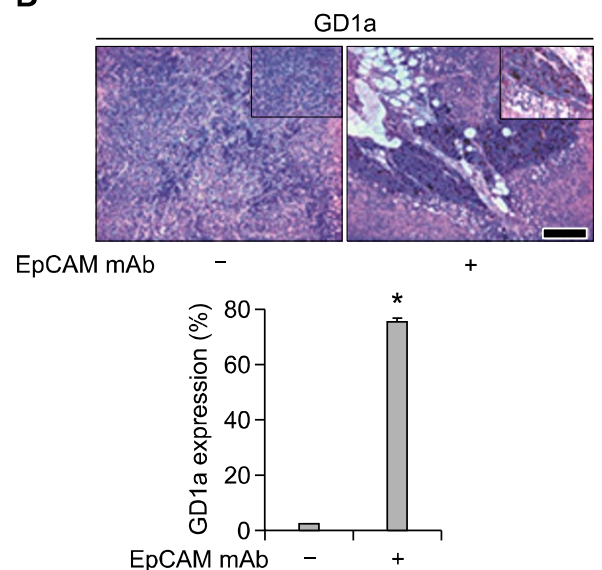

C

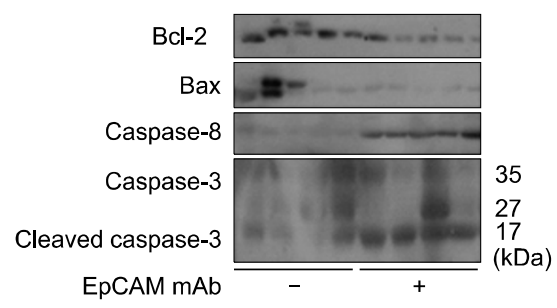

Figure 6. Effects of anti-EpCAM mAb on the expression of ganglioside GD1a in apoptosis of colon cancer tumor tissue analyzed by immunohistochemistry and TUNEL. Apoptotic cell death was determined by immunohistochemistry, DAPI staining and TUNEL assay as described in Methods. (A) The TUNEL-positive (green) cells are a apoptotic cells $(200 \times$ magnification). Apoptotic cells (DAPI-stained, TUNEL-positive cells) were estimated by direct counting of fragmented nuclei after DAPI and TUNEL staining. SW620 colon cancer tumors either untreated or treated with various doses of anti-EpCAM mAb (100 $\mu \mathrm{g})$. GD1a ganglioside expressing cells were examined with the ABC kit. Anit-EpCAM mAb was injected (100 $\mu \mathrm{g} / 2$ days/mouse) into nude mice for 4 weeks. (B) SW620 cancer tumor tissue as a control (200× magnification). Ganglioside GD1a expression was significantly increased in SW620 cancer tumor tissue ( $200 \times$ magnification). (C) An equal amount of total protein (40 $\mu \mathrm{g} / \mathrm{lane}$ ) was subjected to $12 \%$ SDS-PAGE. Expression of Bax, Caspase-3, Caspase-8, Bcl-2, and $\beta$-actin were detected by western blotting using specific antibodies. Here, $\beta$-actin protein was used as an internal control. Each band is representative of 3 independent experimental results. The value is the mean (SD) of 3 experiments, with each performed in triplicate. ${ }^{*} P<0.05$ indicates a statistically significant difference from the control group. Bar indicate $100 \mu \mathrm{m}$.

in tumor weight and volume. In vivo anti-EpCAM $\mathrm{mAb}$ treatment significantly decreased the expression of $\mathrm{Bcl}-2$ and increased the expression of caspase-3 and -8 and Bax, as determined by western blotting. These results show that GD1a expression was significantly increased in anti-EpCAM mAb-treated colon tumor tissue and that anti-EpCAM mAb suppressed the growth of xenograft tumor cells by inducing apoptosis.

We observed apoptotic cell death and inhibition of colon cancer cell growth at anti-EpCAM mAb concentrations of $10 \mu \mathrm{M}$. Anti-EpCAM mAb is suppressing the growth of cancer cells in vivo. For instance, the growth of transplanted SW620 colorectal cancer cells in male nude mice was inhibited by $40 \%$ by i.p. injection of $100 \mu \mathrm{g} /$ mouse anti-EpCAM mAb/day starting 1 week after tumor cell inoculation. The treated mice exhibited no weight loss or other toxicities. The growth suppression of xenograft SW620 cancer cells mediated by anti-
EpCAM mAb correlated with increased apoptotic cell death and the suppression of proliferating cell nuclear antigen and GD1a staining accompanied by an increase in related gene expression in the tumor tissue. Taken together, these results suggest that GM1 and GD1a were closely related to anticancer effects of anti-EpCAM mAb, and further clinical investigation should be conducted to determine its possible chemopreventive and/or therapeutic efficacy against human colon cancer.

\section{Methods}

\section{Cell Culture}

Human colorectal cancer cell, SW620 cell line was obtained from the American Type Culture Collection (ATCC, VA), and were grown in RPMI 1640 with $10 \%$ fetal bovine serum, $100 \mathrm{U} / \mathrm{ml}$ penicillin, and $100 \mu \mathrm{g} / \mathrm{ml}$ streptomycin at $37^{\circ} \mathrm{C}$ in $5 \% \mathrm{CO}_{2}$ humidified air. RAW264.7 cells were ob- 
tained from the ATCC and were grown in RPMI1640 with $10 \%$ fetal bovine serum, $100 \mathrm{U} / \mathrm{ml}$ penicillin, and $100 \mu \mathrm{g} / \mathrm{ml}$ streptomycin at $37^{\circ} \mathrm{C}$ in $5 \% \mathrm{CO}_{2}$ humidified air.

\section{Cell viability assay}

To determine the cell number, human colorectal cancer cells were seeded into 12 -well plates $\left(5 \times 10^{4}\right.$ cells/well $)$, and were treated with anti-EpCAM mAb (R\&D system Inc., MN), RAW264.7 cells (obtained ATCC, Manassas, VA), ganglioside GM1 $(1 \mu \mathrm{M})$ and GD1a $(1 \mu \mathrm{M})$ (Matreya, PA). After $5 \mathrm{~h}$, the cells were trypsinized and pelleted by centrifugation for $5 \mathrm{~min}$ at $1,500 \mathrm{rpm}$. Subsequently, a drop of the suspension was placed in a Neubauer chamber and the viable cancer cells were counted; cells that excluded trypan blue were considered viable, and cells that showed signs of staining were considered dead. Each assay was performed in triplicate.

\section{High-performance thin-layer chromatography}

Ganglioside analysis was performed using a $10 \times 10 \mathrm{~cm}$ high-performance thin-layer chromatography (HPTLC) 5651 plate (Merck, Darmstadt, Germany) with a slight modification of a previous method (Lee et al., 2007). The markers and gangliosides (1 mg protein/lane) purified from SW620 colorectal cancer cells were loaded into the HPTLC plates and developed in chloroform: $\mathrm{MeOH}: 0.25 \%$ $\mathrm{CaCl}_{2} \cdot \mathrm{H}_{2} \mathrm{O}(50: 40: 10$, v/v/v). Gangliosides were visualized using $0.2 \%$ resorcinol, and the expressional density of gangliosides was quantified by HPTLC densitometry analysis (Scion Image software, version beta 4.0.3; Frederick, MD). Gangliosides obtained from murine and bovine brains were used as standards to categorize individual ganglioside species.

\section{Detection of apoptosis}

Detection of apoptosis was done as described elsewhere method (Schuhly et al., 2009). Cells were cultured in 8-chamber slides. After treatment with anti-EpCAM mAb $(40 \mu \mathrm{M})$, RAW264.7 cells, ganglioside GM1 $(1 \mu \mathrm{M})$ and GD1a $(1 \mu \mathrm{M})$ for $24 \mathrm{~h}$, the cells were washed twice with PBS and fixed by incubation in $4 \%$ paraformaldehyde in PBS for $1 \mathrm{~h}$ at room temperature. TdT-mediated dUTP nick and labeling (TUNEL) assays were performed using the in situ Cell Death Detection Kit (Roche Diagnostics $\mathrm{GmbH}$, Mannheim, Germany) according to the manufacturer's instructions. Total number of cells in a given area (cell density) was determined by DAPI staining. The apoptotic index was determined as the number of TUNEL-positive stained cells divided by the total number of cells counted $\times 100$.

\section{Antitumor activity study in an in vivo xenograft animal model}

Six-week-old male BALB/c athymic nude mice were purchased from Japan SLC (Hamamatsu, Japan) and were housed and maintained under sterile conditions in facilities accredited by the American Association for Accreditation of Laboratory Animal Care, in accordance with current regu- lations and standards of Korea Food and Drug Administration. SW620 human colorectal cancer cells were injected subcutaneously $\left(1 \times 10^{7}\right.$ tumor cells $/ 0.1 \mathrm{ml}$ PBS/ animal) with a 27 -gauge needle into the right lower flank of carrier mice. The tumor-bearing nude mice were injected intraperitoneally (i.p.) with anti-EpCAM mAb dissolved in PBS (100 $\mu \mathrm{g} /$ mouse) twice per week for 4 weeks. As a positive control, daunorubicin (DNR) $(100 \mu \mathrm{g} /$ mouse) was also injected once a week. The weight and tumor volume of the animals were monitored twice per week. Tumor volume was measured using calipers and calculated using the formula $\left(A \times B^{2}\right) / 2$, where $A$ is the larger and $B$ is the smaller of the 2 dimensions. At the end of the experiment, the animals were killed by cervical dislocation. The tumors were separated from the surrounding muscles and dermis, excised, and weighed.

\section{Immunohistochemical stain}

All specimens were fixed in formalin and embedded in paraffin for examination. Paraffin-embedded sections were deparaffinized and rehydrated, washed in distilled water, and subjected to heat-mediated antigen retrieval treatment. Endogenous peroxidase activity was quenched by treatment with $2 \%$ hydrogen peroxide in methanol for $15 \mathrm{~min}$ and washing in PBS for 5 min. The sections were blocked for 30 min with $3 \%$ normal horse serum diluted in PBS; the sections were blotted and incubated with primary mouse GD1a and GM1 mAbs (1:200 dilutions) at the appropriate dilution in blocking serum for $4 \mathrm{~h}$ at room temperature and left overnight at $4^{\circ} \mathrm{C}$. The next day slides were washed thrice in PBS for 5 min each and incubated with biotinylated anti-mouse and rabbit antibody for $2 \mathrm{~h}$. The slides were washed in PBS and incubated with the avidin-biotin-peroxidase complex (ABC, Vector Laboratories Inc., Burlingame, CA). The slides were washed and the peroxidase reaction developed with diaminobenzidine and peroxide, counterstained with hematoxylin, mounted in aquamount, and evaluated under a light microscope $(200 \times$; Olympus, Tokyo, Japan). A negative control was performed for every experiment by omitting the primary antibody. All slides were counterstained with hematoxylin. To detect apoptotic cells in tumor tissue, the paraffin-embedded sections were incubated in a mixture of labeling solution (450 $\mu \mathrm{l})$ and enzyme solution $(50 \mu \mathrm{l})$ for $1 \mathrm{~h}$ at $37^{\circ} \mathrm{C}$ and washed thrice in $0.1 \mathrm{M}$ PBS for $5 \mathrm{~min}$ each according to manufacturer instructions. The sections were incubated with the DAPI for $15 \mathrm{~min}$ at $37^{\circ} \mathrm{C}$. Positive TUNEL staining was recorded by counting the number of cells that were positively stained with DAPI in the defined area.

\section{Western bolt analysis}

The SW620 colorectal cancer cells were homogenized in lysis buffer [150 mM NaCl, $1 \%$ Triton X-100, 0.1\% SDS, 1 $\mathrm{mM}$ phenylmethylsulfonyl fluoride (PMSF), $1 \mathrm{mM}$ EDTA, $0.5 \%$ sodium deoxycholate, and $50 \mathrm{mM}$ Tris/ $/ \mathrm{HCl}, \mathrm{pH} 7.4]$, and then centrifuged at $13,000 \mathrm{rpm}$ for $20 \mathrm{~min}$ at room temperature. Proteins $(20 \mu \mathrm{g} / \mathrm{lane})$ were separated on a $7.5 \%$ SDS-PAGE gel and then transferred to a nitrocellulose membrane (Hybond ECL; Amersham Pharmacia Biotech, Piscataway, NJ). The blots were blocked with $5 \%$ 
non-fat dried milk in Tris-buffered saline for $2 \mathrm{~h}$. The membrane was then incubated for $16 \mathrm{~h}$ with a primary antibody: rabbit anti-caspase-8 (Santa Cruz Biotechnology Inc., Delaware, CA), rabbit anti-bax (Santa Cruz Biotechnology Inc.), rabbit anti-caspase-3 (Santa Cruz Biotechnology Inc.), rabbit anti-TNF- $\alpha$ (Santa Cruz Biotechnology Inc.), and mouse monoclonal anti-Bcl-2 (Santa Cruz Biotechnology Inc.), at $4^{\circ} \mathrm{C}$. After the membranes were incubated with BCIT/NBT, immunoreactivity was determined using a Microtek ScanMaker 5 and quantified by densitometry analysis.

\section{Statistical analysis}

All data are presented as mean (SD). Multi-group comparison was performed using one-way ANOVA and two-way ANOVA, followed by Tukey's and Bonferroni post hoc pairwise comparison. A $P$ value $<0.05$ was considered statistically significant. All statistical analyses were performed using GraphPad Prism (Ver. 4.00; GraphPad Software Inc., La Jolla, CA).

\section{Supplemental data}

Supplemental data include a figure and can be found with this article online at http://e-emm.or.kr/article/article_files/ SP-43-12-06.pdf.

\section{Acknowledgements}

This research was supported by a grant (Code\# PJ007187) from the Korean Rural Development Administration, and has been supported by the grant K11050 awarded to Korea Institute of Oriental Medicine (KIOM) from Ministry of Education, Science and Technology (MEST), Republic of Korea.

\section{References}

Balzar M, Winter MJ, de Boer CJ, Litvinov SV. The biology of the 17-1A antigen (Ep-CAM). J Mol Med 1999;77:699-712

Bergsagel PL, Victor-Kobrin C, Timblin CR, Trepel J, Kuehl WM. A murine cDNA encodes a pan-epithelial glycoprotein that is also expressed on plasma cells. J Immunol 1992; 148:590-6

Coffey RN, Watson RW, O'Neill AJ, Mc Eleny K, Fitzpatrick JM. Androgen-mediated resistance to apoptosis. Prostate 2002;53:300-9

Dalerba P, Dylla SJ, Park IK, Liu R, Wang X, Cho RW, Hoey T, Gurney A, Huang EH, Simeone DM, Shelton AA, Parmiani G, Castelli C, Clarke MF. Phenotypic characterization of human colorectal cancer stem cells. Proc Natl Acad Sci USA 2007; 104:10158-63

Dillman RO. Radiolabeled anti-CD20 monoclonal antibodies for the treatment of B-cell lymphoma. J Clin Oncol 2002;20: 3545-57

Dyer MJ. The role of CAMPATH-1 antibodies in the treatment of lymphoid malignancies. Semin Oncol 1999;26:52-7
Feizi T. Demonstration by monoclonal antibodies that carbohydrate structures of glycoproteins and glycolipids are onco-developmental antigens. Nature 1985;314:53-7

Fukuda M. Possible roles of tumor-associated carbohydrate antigens. Cancer Res 1996;56:2237-44

Hakomori S. Tumor malignancy defined by aberrant glycosylation and sphingo(glyco)lipid metabolism. Cancer Res 1996;56:5309-18

Herlyn D, Herlyn M, Ross AH, Ernst C, Atkinson B, Koprowski $\mathrm{H}$. Efficient selection of human tumor growth-inhibiting monoclonal antibodies. J Immunol Methods 1984;73:157-67

Herlyn M, Steplewski Z, Herlyn D, Koprowski H. Colorectal carcinoma-specific antigen: detection by means of monoclonal antibodies. Proc Natl Acad Sci USA 1979;76: 1438-42

Howard DR, Eaves AC, Takei F. Monoclonal antibodies to HLA-DP, DQ, and DR determinants: functional effects on the activation and proliferation of normal and EBV-transformed B cells. Exp Hematol 1986;14:887-95

Hyuga S, Yamagata S, Tai T, Yamagata T. Inhibition of highly metastatic FBJ-LL cell migration by ganglioside GD1a highly expressed in poorly metastatic FBJ-S1 cells. Biochem Biophys Res Commun 1997;231:340-3

Hyuga S, Yamagata S, Takatsu Y, Hyuga M, Nakanishi H, Furukawa K, Yamagata T. Suppression by ganglioside GD1A of migration capability, adhesion to vitronectin and metastatic potential of highly metastatic FBJ-LL cells. Int $J$ Cancer 1999;83:685-91

Kannagi R, Izawa M, Koike T, Miyazaki K, Kimura N. Carbohydrate-mediated cell adhesion in cancer metastasis and angiogenesis. Cancer Sci 2004;95:377-84

Koprowski H, Steplewski Z, Mitchell K, Herlyn M, Herlyn D, Fuhrer P. Colorectal carcinoma antigens detected by hybridoma antibodies. Somatic Cell Genet 1979;5:957-71

Kwak DH, Seo BB, Chang KT, Choo YK. Roles of gangliosides in mouse embryogenesis and embryonic stem cell differentiation. Exp Mol Med 2011;43:379-88

Laine RA, Hakomori S. Incorporation of exogenous glycosphingolipids in plasma membranes of cultured hamster cells and concurrent change of growth behavior. Biochem Biophys Res Commun 1973;54:1039-45

Lee DH, Koo DB, Ko K, Ko K, Kim SM, Jung JU, Ryu JS, Jin JW, Yang HJ, Do SI, Jung KY, Choo YK. Effects of daunorubicin on ganglioside expression and neuronal differentiation of mouse embryonic stem cells. Biochem Biophys Res Commun 2007;362:313-8

Maetzel D, Denzel S, Mack B, Canis M, Went P, Benk M, Kieu C, Papior P, Baeuerle PA, Munz M, Gires O. Nuclear signalling by tumour-associated antigen EpCAM. Nat Cell Biol 2009;11:162-71

Ross AH, Herlyn D, Iliopoulos D, Koprowski H. Isolation and characterization of a carcinoma-associated antigen. Biochem Biophys Res Commun 1986;135:297-303

Schoemaker MH, Ros JE, Homan M, Trautwein C, Liston P, Poelstra K, van Goor H, Jansen PL, Moshage H. Cytokine 
regulation of pro- and anti-apoptotic genes in rat hepatocytes: NF-kappaB-regulated inhibitor of apoptosis protein 2 (clAP2) prevents apoptosis. J Hepatol 2002;36:742-50

Schuhly W, Khan SI, Fischer NH. Neolignans from North American Magnolia species with cyclooxygenase 2 inhibitory activity. Inflammopharmacology 2009;17:106-10

Seol JG, Park WH, Kim ES, Jung CW, Hyun JM, Lee YY, Kim BK. Potential role of caspase-3 and -9 in arsenic trioxidemediated apoptosis in $\mathrm{PCl}-1$ head and neck cancer cells. Int J Oncol 2001;18:249-55

Shah R, Sabanatham S, Bembridge J, Mearns AJ, Shorrock $\mathrm{K}$. Tumor embolism to LAD during pneumonectomy. A case report. J Cardiovasc Surg (Torino) 1996;37:319-21

Shiratori Y, Nakata R, Okano K, Komatsu Y, Shiina S, Kawase T, Sugimoto T, Omata M, Tanaka M. Inhibition of hepatic metastasis of colon carcinoma by asialo GM1-positive cells in the liver. Hepatology 1992;16:469-78

Sievers EL, Larson RA, Stadtmauer EA, Estey E, Löwenberg $B$, Dombret $H$, Karanes C, Theobald M, Bennett JM, Sherman ML, Berger MS, Eten CB, Loken MR, van Dongen $\mathrm{JJ}$, Bernstein ID, Appelbaum FR. Efficacy and safety of gemtuzumab ozogamicin in patients with CD33-positive acute myeloid leukemia in first relapse. J Clin Oncol 2001; 19:3244-54

Staib L, Birebent B, Somasundaram R, Purev E, Braumüller $H$, Leeser C, Küttner N, Li W, Zhu D, Diao J, Wunner W, Speicher D, Beger HG, Song H, Herlyn D. Immunogenicity of recombinant GA733-2E antigen (CO17-1A, EGP, KS1-4, $\mathrm{KSA}, \mathrm{Ep}-\mathrm{CAM}$ ) in gastro-intestinal carcinoma patients. Int J Cancer 2001;92:79-87
Svennerholm L. Ganglioside designation. Adv Exp Med Biol 1980;125:11

Svennerholm L, Bostrom K, Fredman P, Mansson JE, Rosengren B, Rynmark BM. Human brain gangliosides: developmental changes from early fetal stage to advanced age. Biochim Biophys Acta 1989;1005:109-17

Vogel CA, Galmiche MC, Westermann P, Sun LQ, Pèlegrin A, Folli S, Bischof Delaloye A, Slosman DO, Mach JP, Buchegger F. Carcinoembryonic antigen expression, antibody localisation and immunophotodetection of human colon cancer liver metastases in nude mice: a model for radioimmunotherapy. Int J Cancer 1996;67:294-302

Wenqi D, Li W, Shanshan C, Bei C, Yafei Z, Feihu B, Jie L, Daiming F. EpCAM is overexpressed in gastric cancer and its downregulation suppresses proliferation of gastric cancer. J Cancer Res Clin Oncol 2009;135:1277-85

Yamashita T, Budhu A, Forgues M, Wang XW. Activation of hepatic stem cell marker EpCAM by Wnt-beta-catenin signaling in hepatocellular carcinoma. Cancer Res 2007;67: 10831-9

Zaloudik J, Li W, Jacob L, Kieny MP, Somasundaram R, Acres B, Song H, Zhang T, Li J, Herlyn D. Inhibition of tumor growth by recombinant vaccinia virus expressing GA733/CO17-1A/EpCAM/KSA/KS1-4 antigen in mice. Cancer Gene Ther 2002;9:382-9

Zha H, Aime-Sempe C, Sato T, Reed JC. Proapoptotic protein Bax heterodimerizes with $\mathrm{Bcl}-2$ and homodimerizes with Bax via a novel domain (BH3) distinct from $\mathrm{BH} 1$ and $\mathrm{BH} 2$. J Biol Chem 1996;271:7440-4 
EXPERIMENTAL and MOLECULAR MEDICINE, Vol. 44, No. 1, 68, January 2012

http://dx.doi.org/10.3858/emm.2012.44.1.026

\section{Erratum}

Dong Hoon Kwak, Jae-Sung Ryu, Chang-Hyun Kim, Kisung Ko, Jin Yeul Ma, Kyung-A Hwang and Young-Kug Choo

Relationship between ganglioside expression and anti-cancer effects of the monoclonal antibody against epithelial cell adhesion molecule in colon cancer

Exp Mol Med 2011;43:693-701

The authors request to correct the project number PJ007492 (correct one) from PJ007187 (wrong number) on the first line of Acknowlegement.

The authors apologize for any inconvenience they may have caused. 